\title{
Cross-Linking of $\alpha_{2}$-Plasmin Inhibitor to Fibrin by Fibrin-stabilizing Factor
}

\author{
YoICHI SAKATA and NoBUo AOKI, Institute of Hematology and \\ Department of Medicine, Jichi Medical School, Tochigi-Ken, Japan 329-04
}

A B S T R A C T The concentration of $\alpha_{2}$-plasmin inhibitor in blood plasma is higher than that in serum obtained from the blood clotted in the presence of calcium ions, but is the same as that in serum obtained in the absence of calcium ions.

Radiolabeled $\alpha_{2}$-plasmin inhibitor was covalently bound to fibrin only when calcium ions were present at the time of clotting of plasma or fibrinogen. Whereas, when batroxobin, a snake venom enzyme that lacks the ability to activate fibrin-stabilizing factor, was used for clotting fibrinogen, the binding was not observed. When fibrin-stabilizing, factor-deficient plasma was clotted, the specific binding of $\alpha_{2}$-plasmin inhibitor to fibrin did not occur even in the presence of calcium ions and the concentration of $\alpha_{2}$-plasmin inhibitor in serum was the same as that in plasma.

Monodansyl cadaverine, a fluorescent substrate of the fibrin-stabilizing factor, was incorporated into $\alpha_{2}$ plasmin inhibitor by activated fibrin-stabilizing factor.

All these findings indicate that $\alpha_{2}$-plasmin inhibitor is cross-linked to fibrin by activated fibrin-stabilizing factor when blood is clotted. Analysis of $\alpha_{2}$-plasmin inhibitor-incorporated fibrin by sodium dodecyl sulfate gel electrophoresis showed that the inhibitor was mainly cross-linked to polymerized $\alpha$-chains of crosslinked fibrin. Cross-linking of $\alpha_{2}$-plasmin inhibitor to fibrin renders fibrin clot less susceptible to fibrinolysis by plasmin.

\section{INTRODUCTION}

The dissolution of fibrin deposits or thrombin in vivo is achieved by plasmin formed from plasminogen by plasminogen activator that has been added extrinsically for the therapeutic purposes (urokinase and streptokinase) or endogenously generated in the vascular trees (blood activators or vascular activator). Regardless of the manner in which plasminogen is activated, dis-

Received for publication 9 July 1979 and in revised form 1 October 1979. solution of fibrin (fibrinolysis) is believed to be checked or retarded by natural inhibitors of fibrinolysis.

Natural inhibitors of fibrinolysis inhibit the activation of plasminogen to plasmin (inhibitor of plasminogen activation or activator inhibitor) or act upon the plasmin already formed (plasmin inhibitors). Although the presence of the former inhibitors in plasma (1) has not been fully substantiated, the presence of plasmin inhibitors has been firmly established (2).

Among various proteinase inhibitors capable of inhibiting plasmin activity, two inhibitors, $\alpha_{2}$-plasmin inhibitor $\left(\alpha_{2} \mathrm{PI}\right)^{1}$ and $\alpha_{2}$-macroglobulin are considered to be physiologically most important (2). Plasmin generated in a plasma milieu is effectively inhibited by these two inhibitors, therefore fibrinogenolysis does not occur under these conditions.

When fibrin is formed, plasminogen activators and plasminogen are adsorbed to fibrin and plasminogen activation takes place on fibrin molecules to exert an effective fibrinolysis. This process of fibrinolysis is efficiently inhibited by $\alpha_{2}$ PI but not by $\alpha_{2}$-macroglobulin $(2,3)$. This hypothesis was substantiated by the discovery of congenital deficiency of $\alpha_{2} \mathrm{PI}$ (4). The efficient inhibition of fibrinolysis by $\alpha_{2}$ PI has been attributed to the inhibition of binding of plasminogen to fibrin by $\alpha_{2}$ PI $(2,3)$ in addition to the rapid inactivation of plasmin formed during plasminogen activation $(2,5,6)$.

In a brief, preliminary communication (7), we showed that $\alpha_{2}$ PI was adsorbed to fibrin when plasma was clotted and suggested that the adsorption might be another mechanism of the efficient inhibition of fibrinolysis by $\alpha_{2}$ PI.

We now present evidence that $\alpha_{2} \mathrm{PI}$ is bound to fibrin by a covalent linkage formed by activated fibrinstabilizing factor ( $\mathrm{FSF}$, blood coagulation factor XIII, plasma transglutaminase), and suggest that the covalent binding of $\alpha_{2}$ PI to fibrin contributes significantly to the stability of fibrin.

\footnotetext{
${ }^{1}$ Abbreviations used in this paper: $\alpha_{2} \mathrm{PI}, \alpha_{2}$-plasmin inhibitor; FSF, fibrin-stabilizing factor; $\mathrm{MDC}$, monodansyl cadaverine; SDS, sodium dodecyl sulfate.
} 


\section{METHODS}

Fibrinogen. Human fraction I-4 prepared by the method of Blombäck and Blombäck (8) or human Cohn's fraction I (Green Cross Corp., Osaka) was used as fibrinogen preparation after removing contaminating plasminogen from the preparation using lysine-Sepharose (Pharmacia Fine Chemicals, Inc., Piscataway, N. J.) (9). The concentration of FSF present in the solution of $250 \mathrm{mg} / 100 \mathrm{ml}$ of fraction I-4 or Cohn's fraction I was 50 or $80 \%$ of normal standard plasma, respectively, when assayed by an antibody neutralization method (10) using a Clotting Factor XIII-test kit supplied by Behringwerke AG, Marburg. Cold-insoluble globulin was not detected in the fraction I-4 preparation by double immunodiffusion, single radial immunodiffusion or counter immunoelectrophoresis using specific antiserum against cold-insoluble globulin (11). There was also no characteristic band of subunit cold-insoluble globulin with mol wt 215,000 when the preparation was analyzed by sodium dodecyl sulfate gel electrophoresis with reduction (11). Cohn's fraction I was clearly contaminated with cold-insoluble globulin. Fibrinogen was dissolved in barbital-buffered saline $(0.005 \mathrm{M}$ barbital-acetic acid-0.14 M NaCl, pH 7.4) and the concentration was adjusted to $1.5 \%$ (wt/vol) clottable protein.

Thrombin. Purified thrombin was prepared from bovine thrombin preparation (Parke, Davis \& Co., Detroit, Mich.) according to the method of Lundblad (12), and was stored as a $200 \mathrm{U} / \mathrm{ml}$ solution in $50 \%$ glycerol at $-20^{\circ} \mathrm{C}$.

Plasmin. Plasminogen was purified from human whole plasma by affinity chromatography using lysine-coupled Sepharose 4B (13), and was activated with urokinase-coupled Sepharose according to the described method (5). Total conversion of plasminogen to two-chain plasmin form was ascertained by sodium dodecyl sulfate gel electrophoresis with reduction (14). Plasmin thus obtained was stored at $-20^{\circ} \mathrm{C}$ as a 65 caseinolytic $\mathrm{U} / \mathrm{ml}$ solution (15) in buffered saline containing $25 \%$ glycerol. Plasmin was diluted with buffered saline immediately before the use.

Batroxobin. Coagulant enzyme batroxobin purified from snake venom of Bothrops atrox was obtained from Tohbishi Pharmaceutical Co., Tokyo. Coagulant activity was expressed in batroxobin unit, which is equivalent to 0.175 National Institutes of Health (NIH) U of thrombin.

FSF. Human FSF concentrate (fibrogammin) was obtained from Behringwerke AG. $1 \mathrm{U}$ of FSF is defined as the amount of FSF present in $1 \mathrm{ml}$ of normal standard plasma.

Primary amines. Histamine was purchased from Nakarai Chem. Co., Tokyo. N-(5-Aminopentyl)-5-dimethylamino-1naphthalenesulfonamide (monodansyl cadaverine, MDC) was kindly supplied by Dr. T. Urayama, Department of Biochemistry, Toho University School of Medicine, Tokyo.

$\alpha_{2}$ PI. $\quad \alpha_{2}$ PI was purified by the described method (5). The concentration of $\alpha_{2} \mathrm{PI}$ was determined by single radial immunodiffusion using monospecific antiserum to $\alpha_{2} \mathrm{PI}$ and a purified $\alpha_{2}$ PI preparation with a known concentration as a standard (16). Activity of $\alpha_{2}$ PI was determined by a fibrinolytic method (5).

Albumin. Human albumin (fraction V, fatty acid free) was purchased from Miles Laboratories, Inc., Elkhart, Ind.

Plasma and serum. Blood freshly drawn from antecubital veins was divided: one portion was immediately mixed with the powder of EDTA (Wako Pure Chemical Ind., Osaka) in a ratio of $1.86 \mathrm{mg}$ EDTA to $1 \mathrm{ml}$ blood and was centrifuged at $2,000 \mathrm{~g}$ for $20 \mathrm{~min}$ to prepare plasma. Another portion was allowed to stand in a glass test tube for $2 \mathrm{~h}$ at $37^{\circ} \mathrm{C}$, and serum was separated from the clot by centrifugation. Serum was also obtained by clotting $1 \mathrm{ml}$ of EDTA-plasma with $40 \mu \mathrm{l}$ of thrombin $(50 \mathrm{U} / \mathrm{ml})$ or thrombin-calcium mixture (thrombin
$50 \mathrm{U} / \mathrm{ml}, \mathrm{CaCl}_{2}, 0.375 \mathrm{M}$ ). FSF-deficient plasma was kindly supplied by Dr. M. Fujimaki, Department of Clinical Pathology, Tokyo Medical College. The blood was obtained from a patient with congenital deficiency of FSF and immediately mixed with $1 / 10$ vol of $3.8 \%$ sodium citrate to obtain citrated plasma. When the fibrin formed by the addition of thrombin and calcium ions to this plasma was analyzed by sodium dodecyl sulfate gel electrophoresis (14), no formation of $\gamma$-chain dimer of fibrin was observed, indicating the absence of FSF in the patient's plasma. Serum was obtained by incubating $1 \mathrm{ml}$ of plasma at $37^{\circ} \mathrm{C}$ for $2 \mathrm{~h}$ with $25 \mu \mathrm{l}$ of $0.5 \mathrm{M} \mathrm{CaCl}_{2}$. $\alpha_{2}$ PI-deficient plasma was obtained from a patient with congenital deficiency of $\alpha_{2}$ PI (4). Aprotinin (Trasylol, Bayer Chemical, Tokyo) was added to the plasma in a ratio of $5 \mu \mathrm{l}$ aprotinin $(5,000 \mathrm{U} / \mathrm{ml}): 1 \mathrm{ml}$ plasma to avoid spontaneous fibrinolysis when the plasma was clotted.

Radioiodination of protein. Purified $\alpha_{2} \mathrm{PI}$ and fibrinogen (fraction I-4) were radioiodinated by the method of Thorell and Johansson (17) or the solid-state lactoperoxidase method of David (18), respectively, using lactoperoxidase (CalbiochemBehring Corp., American Hoechst Corp., San Diego, Calif.) and ${ }^{125} \mathrm{I}-\mathrm{Na}(17 \mathrm{Ci} / \mathrm{ml})$ (New England Nuclear, Boston, Mass.). The labeled $\alpha_{2}$ PI preparation had the radioactivity of 1.1 $\times 10^{7} \mathrm{cpm} / \mu \mathrm{g}$. Specific activity of $\alpha_{2}$ PI before and after radioiodination was $1136 \mathrm{U} / A_{280}$ and $1,050 \mathrm{U} / A_{280}$, respectively. $\alpha_{2}$ PI concentration of the labeled $\alpha_{2}$ PI preparation was 60 $\mu \mathrm{g} / \mathrm{ml}$. The labeled fibrinogen preparation had a radioactivity of $6.3 \times 10^{4} \mathrm{cpm} / \mu \mathrm{g}$. Clottability $(97 \%)$ was not changed, and fibrinogen concentration of the labeled preparation was 316 $\mathrm{mg} / 100 \mathrm{ml}$ clottable protein.

Measurement of the binding of $\alpha_{2}$ PI to fibrin. When plasma was used, $1 \mathrm{ml}$ of plasma was mixed in a counting vial for radioactivity with $5 \mu$ l of radiolabeled $\alpha_{2}$ PI and the mixture was clotted by the addition of $40 \mu \mathrm{l}$ of thrombin $(50 \mathrm{U} / \mathrm{ml})$ or a thrombin-calcium mixture (thrombin $50 \mathrm{U} / \mathrm{ml}, \mathrm{CaCl}_{2} 0.375$ M). The clotting mixture was incubated at $37^{\circ} \mathrm{C}$ for $30 \mathrm{~min}$. When fibrinogen preparations were used, $135 \mu \mathrm{l}$ of fibrinogen (1.5\%) was mixed with $5 \mu \mathrm{l}$ of radiolabeled $\alpha_{2} \mathrm{PI}, 40 \mu \mathrm{l}$ of nonlabeled $\alpha_{2}$ PI $(1.5 \mathrm{mg} / \mathrm{ml})$ and $810 \mu \mathrm{l}$ of buffered saline containing calcium chloride or no calcium chloride. The mixture was clotted with $10 \mu \mathrm{l}$ of thrombin $(200 \mathrm{U} / \mathrm{ml})$ and incubated at $37^{\circ} \mathrm{C}$ for $30 \mathrm{~min}$. In some experiments $400 \mu \mathrm{l}$ of batroxobin $(20 \mathrm{U} / \mathrm{ml})$ were used instead of thrombin.

After counting the total radioactivity, the formed clot was separated by centrifugation. The clot was then squeezed with a bamboo stick against the wall of the tube to express as much fluid as possible. The fibrin was subsequently soaked in buffered saline to wash out unbound materials with frequent changes of buffered saline. The total volume of buffered saline used to wash one clot was $25 \mathrm{ml}$. After washing, the clot was counted for radioactivity. Radioactivity was counted by Auto-Well gamma system, Aloka JDC-752 (Aloka Co., Tokyo). The amount of $\alpha_{2}$ PI bound to fibrin was calculated from the radioactivity remaining in the washed clot and expressed as a percentage of the original total radioactivity in the clotting mixture. The studies were carried out in triplicate. The original radioactivity in the clotting mixture was 80,817 $\pm 4,747 \mathrm{cpm}$.

Measurement of plasmin-induced clot lysis. $1.2 \mathrm{ml}$ of fibrinogen (fraction $\mathrm{I}-4,9.8 \mathrm{mg} / \mathrm{ml}$ ) was mixed with $40 \mu \mathrm{l}$ of radiolabeled fibrinogen. $100 \mu \mathrm{l}$ of this mixture was mixed with $25 \mu \mathrm{l}$ of $\alpha_{2}$ PI $(1.1 \mathrm{mg} / \mathrm{ml}$ or its dilutions) or buffered saline, $245 \mu$ l of buffered saline containing $2 \%$ human albumin, and $20 \mu \mathrm{l}$ of calcium chloride $(0.1 \mathrm{M})$. The mixture was clotted with $10 \mu \mathrm{l}$ of thrombin $(100 \mathrm{U} / \mathrm{ml})$ and incubated at $37^{\circ} \mathrm{C}$ for $30 \mathrm{~min}$. The purpose of including albumin in the clotting mixture was to stabilize $\alpha_{2} \mathrm{PI}$ and preserve its inhibitor activity during the incubation. The clot was squeezed, washed, 
and counted for radioactivity in the same way as described in the preceding section except that the first two washes contained $2 \%$ albumin. Albumin was effective in reducing unspecific noncovalent binding of $\alpha_{2}$ PI to fibrin. The clot was then placed in $360 \mu \mathrm{l}$ buffered saline $(0.05 \mathrm{M}$ Tris-HCl- 0.15 $\mathrm{M} \mathrm{NaCl}, \mathrm{pH} 7.4)$, to which $25 \mu \mathrm{l}$ of plasmin $(4.3 \mathrm{U} / \mathrm{ml}, 0.4$ $\mathrm{mg} / \mathrm{ml}$ ) was added, and incubated at $37^{\circ} \mathrm{C}$ for lysis. Aliquots of $50 \mu \mathrm{l}$ were removed at intervals for radioactive counting. Results were expressed as percent release of radiolabel, which was calculated from the counts, applying a correction for the influence of repeated subsampling upon the volume of the supernatant. Controls were run replacing plasmin with buffered saline. The control values were constantly low $(<5 \%)$ during the incubation, and the plasmin-induced release was calculated by subtracting the control value from that of the test. The radioactivity of the original clot was $710,417 \pm 20,951$ cpm. In the parallel experiments, radiolabeled fibrinogen was replaced by radiolabeled $\alpha_{2}$ PI and the binding of $\alpha_{2}$ PI to fibrin was estimated as described in the preceding section. Noncovalent binding of $\alpha_{2} \mathrm{PI}$ in the washed clot was estimated by eluting the washed clot with $8 \mathrm{M}$ urea.

Gel electrophoresis. Sodium dodecyl sulfate (SDS) polyacrylamide gel electrophoresis was performed with $5 \%$ polyacrylamide gels according to the method of Weber and Osborn (14). Before electrophoresis, the proteins were denatured and reduced by incubation for $30 \mathrm{~min}$ at $100^{\circ} \mathrm{C}$ with $2 \% \mathrm{SDS}$ and 5\% 2-mercaptoethanol.

Immunoelectrophoresis. Immunoelectrophoresis was carried out in $1 \%$ agarose in $\mathrm{pH} 8.6$ barbital buffer $(\mathrm{I}=0.05)$ on a glass slide. Electrophoresis was run with a constant current of $3 \mathrm{~mA} / \mathrm{cm}$ width for $1 \mathrm{~h}$. Specific antiserum of rabbits against $\alpha_{2}$ PI (5) was used.

Fluorescent photography. Photographs of gels containing proteins labeled with fluorescent amine, MDC, were taken with Fuji film ASA 400 (Fuji Film Co., Tokyo) and a yellow filter (Asahi Pentax filter 49 "Y2", Asahi Pentax Co., Tokyo); a long wavelength ultraviolet box (Ultra-violet Products, Inc., San Gabriel, Calif.) was the light source.

\section{RESULTS}

Difference of $\alpha_{2} P I$ concentrations between plasma and serum. When 11 normal individuals were examined, $\alpha_{2}$ PI concentration in serum was lower than that in plasma of the same individual and the difference was $\sim 24 \%$ on average of the concentration in plasma (Table I). However, there was no appreciable difference observed between plasma and serum when FSFdeficient blood was examined (Table I).

$\alpha_{2}$ PI concentration in serum prepared by clotting plasma with thrombin plus calcium ions was compared with that in serum prepared by thrombin only. When nine pairs of the serum samples from normal individuals were examined, the serum samples prepared in

TABLE I

Difference of $\alpha_{2}$ PI Concentration between Plasma and Serum

\begin{tabular}{lccc}
\hline & Plasma & Serum & Difference \\
\hline Normal & $6.9 \pm 0.6^{*}$ & $5.3 \pm 0.7$ & $1.6 \pm 0.4$ \\
FSF deficiency & 5.9 & 5.8 & 0.1
\end{tabular}

* Mean \pm SD $(n=11)$. All values are expressed as $\mathrm{mg} / 100 \mathrm{ml}$.
TABLE II

$\alpha_{2} P I$ Concentrations in Sera Prepared by Clotting Plasma with Thrombin in the Presence or Absence of Calcium Ions

\begin{tabular}{lccc}
\hline \multirow{2}{*}{ Samples } & \multicolumn{2}{c}{ Calcium ions } & \\
\cline { 2 - 3 } & Absent & Present & Difference \\
\hline Normal & $6.3 \pm 0.6^{*}$ & $4.2 \pm 0.6$ & $2.1 \pm 0.6$ \\
FSF deficiency & 6.1 & 5.8 & 0.3 \\
\hline
\end{tabular}

${ }^{*}$ Mean $\pm \operatorname{SD}(n=9)$. All values are expressed as $\mathrm{mg} / 100 \mathrm{ml}$.

the presence of calcium ions had lower concentrations of $\alpha_{2}$ PI than those in the serum samples prepared in the absence of calcium ions and the average difference was $33 \%$ (Table II). No appreciable difference was found between these two kinds of serum samples if they were obtained from a patient with congenital deficiency of FSF (Table II).

Binding of $\alpha_{2} P I$ to fibrin. Binding of $\alpha_{2} P I$ to fibrin was examined by clotting plasma with thrombin in the presence or absence of calcium ions. In the absence of calcium ions only about $2 \%$ of $\alpha_{2} \mathrm{PI}$ in normal plasma remained bound to fibrin after washing with buffered saline. In the presence of $5 \mathrm{mM}$ calcium ions the binding was increased and $\sim 22 \%$ of $\alpha_{2} \mathrm{PI}$ in plasma were bound to fibrin when plasma was clotted (Table III). Thus, the amount of $\alpha_{2}$ PI bound to fibrin was dependent on whether calcium ions were present or not when normal plasma was clotted. However, when FSF-deficient plasma was clotted, calcium-dependent binding of $\alpha_{2}$ PI to fibrin was not evident and there was no significant difference of the binding between the presence and the absence of calcium ions (Table III).

When a fibrinogen preparation (Fraction I-4 or Cohn's fraction I) was clotted by thrombin in the presence of calcium ions, the differential binding of $\alpha_{2} \mathrm{PI}$ to fibrin was similarly observed as using normal plasma (Table III). The binding in the presence of $5 \mathrm{mM}$ calcium ions was $\sim 10$-fold greater than the binding in the ab-

TABLE III

Binding of $\alpha_{2} P I$ to Fibrin in the Presence or Absence of Calcium Ions

\begin{tabular}{lcc}
\hline \multirow{2}{*}{\multicolumn{1}{c}{ Samples }} & \multicolumn{2}{c}{ Calcium ions } \\
\cline { 2 - 3 } & Present & Absent \\
\hline Plasma & \multicolumn{2}{c}{} \\
$\quad$ Normal & $21.5 \pm 1.8^{*}$ & $1.7 \pm 0.7$ \\
$\quad$ FSF deficiency & 2.4 & 1.8 \\
Fraction I-4 & $32.1 \pm 3.8$ & $3.2 \pm 0.1$ \\
Cohn I & $16.0 \pm 0.6$ & $1.6 \pm 0.2$ \\
Cohn I (clotted by batroxobin) & 4.7 & 4.2 \\
\hline
\end{tabular}

* Mean $\pm \operatorname{SD}(n=6)$. 


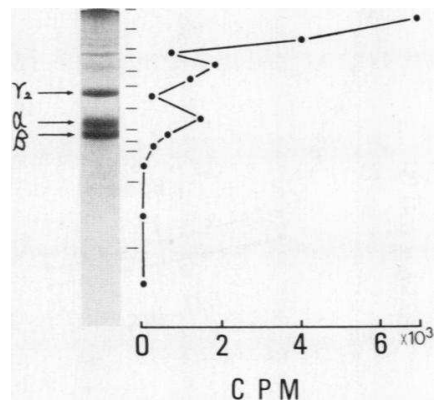

FIGURE 1 Incorporation of $\alpha_{2} \mathrm{PI}$ into cross-linked fibrin. $1 \mathrm{mg}$ of fibrinogen (fraction I-4), $50 \mu \mathrm{g}$ of $\alpha_{2}$ PI containing radiolabeled $\alpha_{2}$ PI, $1.25 \mu \mathrm{mol} \mathrm{CaCl}$, and $1.5 \mathrm{U}$ thrombin in buffered saline were mixed and incubated at $37^{\circ} \mathrm{C}$ for $20 \mathrm{~min}$. The total volume was $0.5 \mathrm{ml}$. The clot formed was washed thoroughly and subsequently subjected to SDS gel electrophoresis. After staining, the gel was sliced at various levels indicated by short horizontal lines on the right of the figure. Count of radioactivity of each slice is shown as counts per minute.

sence of calcium ions (Table III). The increase of calcium ion concentration from 5 to $50 \mathrm{mM}$ did not change appreciably the binding ratio. The presence of 6 -aminohexanoic acid $(20 \mathrm{mM})$ in the clotting mixture did not interfere with the binding of $\alpha_{2}$ PI to fibrin.

When batroxobin, which is unable to activate FSF, was used instead of thrombin for clotting fibrinogen, the binding of $\alpha_{2}$ PI to fibrin was very small regardless of the presence or absence of calcium ions (Table III).

The fibrin formed by thrombin in the presence of

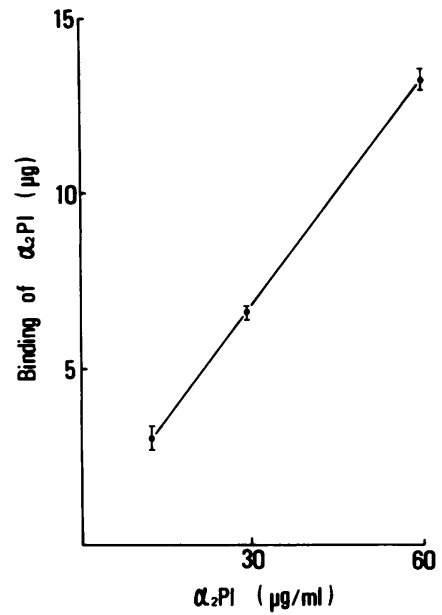

FIGURE 2 Relationship between $\alpha_{2}$ PI concentration and the binding of $\alpha_{2}$ PI. $900 \mu \mathrm{l}$ of $\alpha_{2}$ PI-deficient citrated plasma, 40 $\mu \mathrm{l}$ of $\alpha_{2} \mathrm{PI}$ of various concentrations containing radiolabeled $\alpha_{2} \mathrm{PI}, 20 \mu \mathrm{l}$ of $0.5 \mathrm{M} \mathrm{CaCl}_{2}$, and $40 \mu \mathrm{l}$ of buffered saline containing $3 \mathrm{U}$ of thrombin were mixed and incubated at $37^{\circ} \mathrm{C}$ for $20 \mathrm{~min}$. Fibrinogen concentration in the plasma was 200 $\mathrm{mg} / 100 \mathrm{ml}$. The binding of $\alpha_{2}$ PI to fibrin was determined as described in Methods. The amount of $\alpha_{2}$ PI bound to fibrin was calculated from the binding ratio and the total amount of $\alpha_{2}$ PI present in the clotting mixture. calcium ions was subjected to SDS gel electrophoresis after washing the clot. Distributions of protein and radioactivity in the gel are shown in Fig. 1. Radioactivity was mainly distributed over the region of high molecular weight polymers of $\alpha$-chain of cross-linked fibrin.

Influence of $\alpha_{2}$ PI concentrations on the binding of $\alpha_{2} P I$. When $\alpha_{2}$ PI was added in increasing amounts to $\alpha_{2}$ PI-deficient plasma up to the normal concentration $(6 \mathrm{mg} / 100 \mathrm{ml})$, the amount of $\alpha_{2}$ PI bound to fibrin increased in direct proportion to the amount of $\alpha_{2} \mathrm{PI}$ added (Fig. 2).

Influence of fibrinogen concentration on the binding of $\alpha_{2} P I$. The binding of $\alpha_{2}$ PI to fibrin was determined with various concentrations of fibrinogen in the clotting mixture. With a fixed concentration of $\alpha_{2} \mathrm{PI}$ and excess amounts of FSF, the amount of $\alpha_{2}$ PI bound to fibrin was dependent on the concentration of fibrinogen until the fibrin is "saturated" with $\alpha_{2}$ PI (Fig. 3).

Effect of FSF concentration on the binding of $\alpha_{2} P I$ to fibrin. Various amounts of FSF concentrates were added to FSF-deficient plasma. When these plasmas with various concentrations of FSF were clotted by thrombin and calcium ions, the amount of $\alpha_{2}$ PI bound to fibrin was directly proportional to the amount of FSF added until FSF concentration reached $\sim 8 \%$ of normal concentration in plasma, where the increase started to level off (Fig. 4).

Inhibition of the binding of $\alpha_{2}$ PI by primary amines. Histamine and fluorescent primary amine, MDC, were tested for their effects on the binding of $\alpha_{2}$ PI to fibrin. These primary amines are known to be substrates for activated FSF and specifically inhibit the FSF-catalyzed cross-linking of fibrin. The results are shown in Fig. 5.

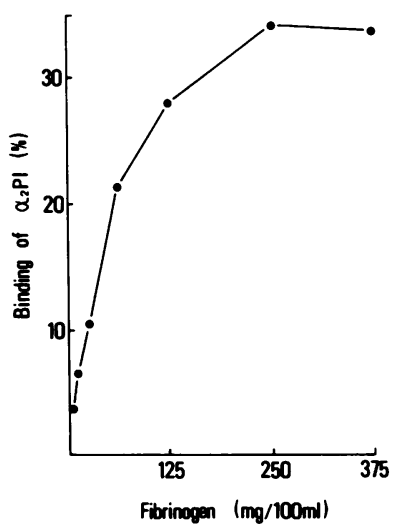

Figure 3 Relationship between fibrinogen concentration and the binding of $\alpha_{2}$ PI. $100 \mu \mathrm{g}$ of $\alpha_{2}$ PI containing radiolabeled $\alpha_{2}$ PI, $1 \mathrm{U}$ of FSF, $5 \mu \mathrm{mol}$ of $\mathrm{CaCl}_{2}$, various amounts of fibrinogen (fraction I-4) and $3 \mathrm{U}$ of thrombin in buffered saline were mixed and incubated at $37^{\circ} \mathrm{C}$ for $20 \mathrm{~min}$. The total volume was $1 \mathrm{ml}$. The binding of $\alpha_{2}$ PI to fibrin was determined as described in Methods. 
These amines inhibited the binding of $\alpha_{2} \mathrm{PI}$ in a dosedependent fashion.

To see if $\alpha_{2}$ PI was also a substrate for activated FSF, $\alpha_{2}$ PI was incubated with FSF concentrate, thrombin, calcium ions, and MDC in the presence of reduced glutathion. The mixture was subsequently subjected to SDS gel electrophoresis and immunoelectrophoresis. The protein band of $\alpha_{2} \mathrm{PI}$ or the protein precipitated specifically with anti- $\alpha_{2} \mathrm{PI}$ antiserum were fluorescently labeled (Fig. 6), indicating that the fluorescent amine was being incorporated into $\alpha_{2}$ PI. The incorporation was catalyzed by activated FSF, because no fluorescent labeling was observed in the absence of calcium ions, thrombin, or FSF.

Resistance of $\alpha_{2} P I$-cross-linked fibrin to plasmin. Susceptibilities to plasmin digestion of fibrin crosslinked to $\alpha_{2} \mathrm{PI}$ and fibrin not cross-linked to $\alpha_{2} \mathrm{PI}$ were examined by clotting radiolabeled fibrinogen with thrombin and calcium ion in the presence or absence of $\alpha_{2}$ PI. Fibrinogen concentration and the maximum concentration of $\alpha_{2}$ PI used in the clotting mixture were 262 and $6.9 \mathrm{mg} / 100 \mathrm{ml}$, respectively. These are normal values in plasma. The fibrin clots thus formed were thoroughly washed to remove unbound $\alpha_{2}$ PI. In the parallel experiments, noncovalently bound $\alpha_{2}$ PI was found to be very low: $<1 \%$ of the original amount of $\alpha_{2} \mathrm{PI}$ in the clotting mixture, whereas $30 \%$ was covalently linked to fibrin. The clots were subsequently subjected to plasmin-catalyzed fibrinolysis (Fig. 7). Release of

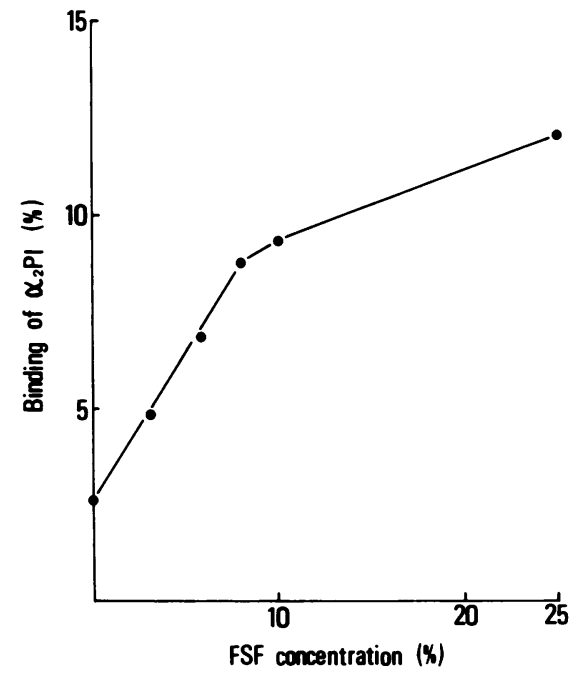

Figure 4 Relationship between FSF concentration and the binding of $\alpha_{2}$ PI. $900 \mu$ l of FSF-deficient plasma containing a trace amount of radiolabeled $\alpha_{2}$ PI, $50 \mu$ l of FSF of various concentrations, $20 \mu \mathrm{l}$ of $0.5 \mathrm{M} \mathrm{CaCl}_{2}$, and $30 \mu$ l of buffered saline containing $1.5 \mathrm{U}$ of thrombin were mixed and incubated at $37^{\circ} \mathrm{C}$ for $20 \mathrm{~min}$. FSF concentrations are expressed as percentage of normal pooled plasma. Fibrinogen concentration in the plasma was $246 \mathrm{mg} / 100 \mathrm{ml}$. The binding of $\alpha_{2} \mathrm{PI}$ to fibrin was determined as described in Methods.

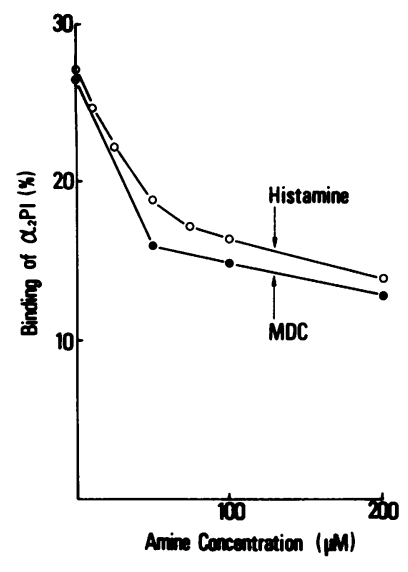

FIGURE 5 Inhibition of $\alpha_{2}$ PI binding by histamine and MDC. $2.5 \mathrm{mg}$ of fibrinogen (fraction I-4), $84 \mu \mathrm{g}$ of $\alpha_{2} \mathrm{PI}$ containing radiolabeled $\alpha_{2}$ PI, various amounts of histamine or MDC, 5 $\mu \mathrm{mol}$ of $\mathrm{CaCl}_{2}$ and $3 \mathrm{U}$ of thrombin in buffered saline were mixed and incubated at $37^{\circ} \mathrm{C}$ for $20 \mathrm{~min}$. The total volume was $1 \mathrm{ml}$. The binding of $\alpha_{2}$ PI to fibrin was determined as described in Methods.

radiolabel, which is an indicator of fibrinolysis, was suppressed by cross-linked $\alpha_{2} \mathrm{PI}$, and the degree of suppression was dependent on the amount of cross-linked $\alpha_{2}$ PI (Fig. 7).

\section{DISCUSSION}

When $\alpha_{2}$ PI concentration in serum prepared from spontaneously clotted normal blood was compared with that

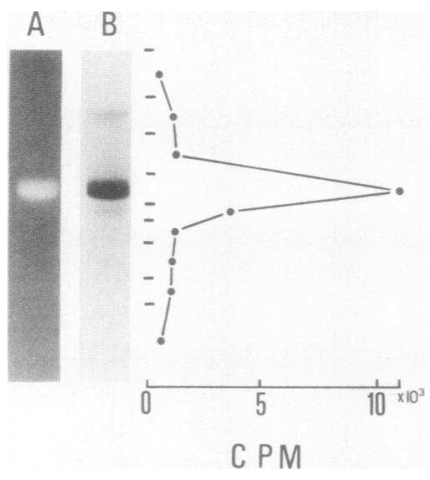

FIgURE 6 Incorporation of MDC into $\alpha_{2}$ PI. $80 \mu \mathrm{g}$ of $\alpha_{2}$ PI containing radiolabeled $\alpha_{2} \mathrm{PI}, 0.2 \mu \mathrm{mol}$ of MDC, $0.5 \mathrm{U}$ of FSF, $2.5 \mu \mathrm{mol}$ of reduced glutathion, $0.5 \mu \mathrm{mol}$ of $\mathrm{CaCl}_{2}$, and $3 \mathrm{U}$ of thrombin in buffered saline were mixed and incubated at $25^{\circ} \mathrm{C}$ for $1 \mathrm{~h}$ in a dark place. The total volume was $100 \mu \mathrm{l}$. After incubation, the reaction was stopped by an addition of $120 \mu \mathrm{l}$ of $0.01 \mathrm{M}$ phosphate buffer, pH 7.4, containing $1 \%$ EDTA, 2\% SDS, and 8\% 2-mercaptoethanol. After heating at $100^{\circ} \mathrm{C}$ for $30 \mathrm{~min}, 2$ samples of $20 \mu \mathrm{l}$ each were subjected to SDS gel electrophoresis. After electrophoresis, one gel was fixed and photographed for fluorescence (A). Another gel was fixed, stained, and sliced at various levels indicated on the right of the figure. Count of radioactivity of each slice is shown as counts per minute. 
$\mathbf{A}$

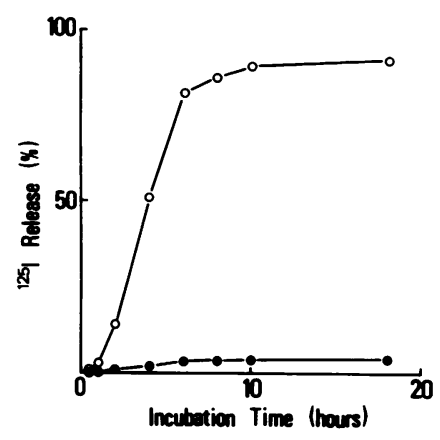

B

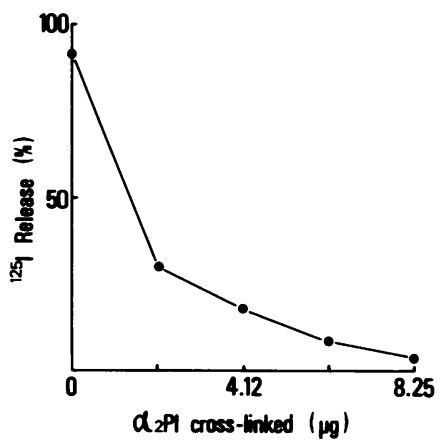

FIGURE 7 Plasmin-induced lysis of cross-linked fibrin clots measured by release of percentage of radiolabel. $1.1 \mathrm{mg}$ of fibrinogen containing radiolabeled fibrinogen was clotted with thrombin plus calcium ions in the absence or presence of various amounts of $\alpha_{2}$ PI. The clot formed was thoroughly washed, and subjected to plasmin-catalyzed fibrinolysis. Plasmin-induced release of radiolabel was measured. In the parallel experiments, the amount of $\alpha_{2}$ PI cross-linked to fibrin was estimated for each set of experiments. For details see Methods. (A) Time-course of release of radiolabel. O, Fibrin not cross-linked to $\alpha_{2}$ PI. - , Fibrin cross-linked to $\alpha_{2}$ PI (cross-linked $\alpha_{2}$ PI 8.25 $\mu \mathrm{g}$ ). (B) Relationship between the amount of $\alpha_{2}$ PI cross-linked to fibrin and the release of radiolabel after $10 \mathrm{~h}$ of incubation.

in plasma, serum was found to contain less $\alpha_{2}$ PI than plasma. When sera were prepared by clotting normal plasmas with thrombin in the presence or the absence of calcium ions, $\alpha_{2} \mathrm{PI}$ concentration in serum formed in the presence of calcium ions was less than that in serum prepared in the absence of calcium ions. However, when FSF-deficient plasma and serum were compared, there was no appreciable difference in $\alpha_{2}$ PI concentrations. Furthermore, when sera were prepared by clotting FSF-deficient plasma with thrombin in the presence or the absence of calcium ions, there was no significant difference in $\alpha_{2}$ PI concentrations between these two kinds of serum.

These findings suggest that $\alpha_{2}$ PI is specifically bound to fibrin by the action of activated FSF because FSF can be activated by thrombin only if calcium ions are present (19). The suggestion was supported by the finding that radiolabeled $\alpha_{2}$ PI was specifically bound to fibrin when normal plasma was clotted by thrombin in the presence of calcium ions but not when normal plasma was clotted in the absence of calcium ions or FSF-deficient plasma was clotted. Furthermore, when fibrinogen was clotted by batroxobin, which is unable to activate FSF, there was no specific binding of $\alpha_{2} \mathrm{PI}$ to fibrin.

The binding of $\alpha_{2}$ PI was dependent on the concentrations of FSF, $\alpha_{2} \mathrm{PI}$, and fibrinogen in the clotting mixture (Fig. 2, 3, and 4). These findings together with the failure to elute the bound $\alpha_{2} \mathrm{PI}$ from fibrin with $8 \mathrm{M}$ urea (7) suggest that $\alpha_{2} \mathrm{PI}$ is enzymatically cross-linked to fibrin by activated FSF.

$\alpha_{2}$ PI seemed to be cross-linked mainly to the crosslinked polymers of $\alpha$-chain of fibrin because radiola- beled $\alpha_{2}$ PI was found associated mainly with highly polymerized $\alpha$-chains in SDS gel electrophoresis (Fig. 1). Exact sites in the chains where $\alpha_{2}$ PI can be linked are not known. Cold-insoluble globulin is also crosslinked to fibrin (20), but $\alpha_{2}$ PI cross-linking was not mediated by cold-insoluble globulin because fibrinogen preparation (fraction I-4) used in the present study was not contaminated by cold-insoluble globulin.

FSF belongs to the class of calcium ion-dependent enzymes called transglutaminases and catalyzes the transfer reaction involving lysyl residues in proteins and peptides as amine donors and glutamyl residues as amine acceptors, thus resulting in the formation of $\gamma$-glutamyl- $\epsilon$-lysine peptide bonds between adjacent fibrin monomers, converting noncovalently linked fibrin to a covalently linked form (19). Various primary amines including synthetic fluorescent amines can be used as amine donors in this reaction and are known to inhibit competitively the enzymatic cross-linking of fibrin (21). In the present study, these primary amines were shown to inhibit also the binding of $\alpha_{2} \mathrm{PI}$ to fibrin in a dose-dependent fashion (Fig. 5). This is another evidence for FSF-catalyzed binding of $\alpha_{2}$ PI to fibrin.

When $\alpha_{2}$ PI was incubated with FSF, thrombin, and calcium ion in the presence of fluorescent amine donor, MDC, fluorescent labeling of $\alpha_{2}$ PI took place (Fig. 6). Fluorescent labeling was not found either in the absence of FSF or in the absence of calcium ion. This indicates that FSF activated by thrombin and calcium ion catalyzed the incorporation of fluorescent MDC into $\alpha_{2} \mathrm{PI}$ at the $\gamma$-glutamyl residues of the molecule. This also suggests that $\alpha_{2} \mathrm{PI}$ is playing the part of amine acceptor in the reaction of FSF-catalyzing binding to 
fibrin. Whether or not $\alpha_{2} \mathrm{PI}$ is also playing the part of amine donor in the reaction is not known at the present time. $\alpha_{2}$-Macro-globulin was also shown to be fluorescently labeled by FSF when plasma was clotted in the presence of MDC and calcium ion (22). However, no evidence was found for cross-linking of $\alpha_{2}$-macroglobulin to fibrin when plasma was clotted (22).

To determine if cross-linking of $\alpha_{2}$ PI to fibrin makes fibrin less susceptible to plasmin-catalyzed fibrinolysis, fibrin cross-linked to $\alpha_{2} \mathrm{PI}$ and fibrin not cross-linked to $\alpha_{2}$ PI were subjected to lysis by plasmin. Release of radiolabel from ${ }^{125}$ I-labeled fibrin clots, which may be the most reliable indicator of fibrinolysis (23), was suppressed by cross-linked $\alpha_{2} \mathrm{PI}$ and the degree of suppression was dependent on the amount of cross-linked $\alpha_{2}$ PI (Fig. 7). The amount of plasmin used was nearly equimolar to the maximum amount of cross-linked $\alpha_{2} \mathrm{PI}$ used in the experiments. Plasmin-induced fibrinolysis was almost totally suppressed by this amount of crosslinked $\alpha_{2}$ PI (Fig. 7A), suggesting that $\alpha_{2}$ PI retains its full activity after its cross-linking to fibrin.

The amount of $\alpha_{2}$ PI noncovalently bound to fibrin in the washed clot was very small $(<1 \%$ of the total amount of $\alpha_{2}$ PI in the clotting mixture) and its contribution to the inhibition of plasmin was negligible since plasmin used was at least 30 times in molar excess of noncovalently bound $\alpha_{2}$ PI. Furthermore, no significant difference in lysis rate of noncross-linked fibrin was observed whether the noncovalently bound $\alpha_{2}$ PI was present or not (data not shown).

The controversial results reported by several authors regarding the influence of fibrin cross-linking on fibrinolysis could be explained at least partly by FSF catalyzed binding of $\alpha_{2} \mathrm{PI}$ to fibrin. It has been assumed that cross-linking by FSF makes fibrin less susceptible to lysis by fibrinolytic enzymes, especially to plasminogen activators (23-27). However, recent studies using purified protein components revealed no difference in resistance to lysis of highly cross-linked and noncross-linked fibrin $(28,29)$. In the former studies designed to give evidence for the increase of resistance to fibrinolysis by fibrin cross-linking, plasma rather than purified fibrinogen was used and therefore the reduced susceptibility of cross-linked fibrin to fibrinolysis might be explained by FSF catalyzed binding of $\alpha_{2}$ PI to fibrin.

\section{ACKNOWLEDGMENTS}

We gratefully acknowledge the cooperation of Doctors $\mathbf{M}$. Matsuda and T. Tamaki and the technical assistance of Ms. K. Tateno. We are also grateful to Doctors T. Urayama and M. Fujimaki for their valuable discussions and advice.

This work was supported in part by Scientific Research Grants from the Ministry of Education of the Government of Japan and by Yamanouchi Foundation for Research on Metabolic Disorders.

\section{REFERENCES}

1. Hedner, U. 1973. Studies on an inhibitor of plasminogen activation in human serum. Thromb. Diath. Haemorrh. 30: $414-424$.

2. Aoki, N. 1979. Natural inhibitors of fibrinolysis. Prog. Cardiovasc. Dis. 21: 267-286.

3. Aoki, N., M. Moroi, and K. Tachiya. 1978. Effects of $\alpha_{2}$ plasmin inhibitor on fibrin clot lysis. Its comparison with $\alpha_{2}$-macroglobulin. Thromb. Haemostasis. 39: 22-31.

4. Aoki, N., H. Saito, T. Kamiya, K. Koie, Y. Sakata, and M. Kobakura. 1979. Congenital deficiency of $\alpha_{2}$-plasmin inhibitor associated with severe hemorrhagic tendency. J. Clin. Invest. 63: 877-884.

5. Moroi, M., and N. Aoki. 1976. Isolation and characterization of $\alpha_{2}$-plasmin inhibitor from human plasma. A novel proteinase inhibitor which inhibits activator-induced clot lysis. J. Biol. Chem. 251: 5956-5965.

6. Aoki, N., M. Moroi, M. Matsuda, and K. Tachiya. 1977. The behavior of $\alpha_{2}$-plasmin inhibitor in fibrinolytic states. J. Clin. Invest. 60: 361-369.

7. Sakata, Y., K. Tateno, T. Tamaki, and N. Aoki. 1979. Calcium-dependent binding of $\alpha_{2}$-plasmin inhibitor to fibrin. Thromb. Res. 16: 279-282.

8. Blombäck, B., and M. Blombäck. 1956. Purification of human and bovine fibrinogen. Ark. Kemi. 10: 415-443.

9. Matsuda, M., S. Iwanaga, and S. Nakamura. 1972. A simple, large scale method for preparation of plasminogenfree fibrinogen. Thromb. Res. 1: 619-630.

10. Bohn, H., and J. Haupt. 1968. Eine quantitative Bestimmung von Faktor XIII mit Anti-Faktor XIII Serum. Thromb. Diath. Haemorrh. 19: 309-315.

11. Matsuda, M., N. Yoshida, N. Aoki, and K. Wakabayashi. 1978. Distribution of cold-insoluble globulin in plasma and tissues. Ann. N. Y. Acad. Sci. 312: 74-92.

12. Lundblad, R. L. 1971 . A rapid method for the purification of bovine thrombin and the inhibition of the purified enzyme with phenyl methyl sulfonyl fluoridide. Biochemistry. 10: 2501-2505.

13. Brockway, W. J., and F. J. Castellino. 1972. Measurement of the binding of antifibrinolytic amino acids to various plasminogens. Arch. Biochem. Biophys. 151: 194-199.

14. Weber, K., and M. Osborn. 1969. The reliability of molecular weight determinations by dodecyl sulfate-polyacrylamide gel electrophoresis. J. Biol. Chem. 244: 4406-4412.

15. Remmert, L. F., and P. P. Cohen. 1949. Partial purification and properties of a proteolytic enzyme of human serum. J. Biol. Chem. 181: 431-448.

16. Aoki, N., and T. Yamanaka. 1978. The $\alpha_{2}$-plasmin inhibitor levels in liver diseases. Clin. Chim. Acta. 84: 99- 105.

17. Thorell, J. I., and B. G. Johansson. 1971. Enzymatic iodination of polypeptides with ${ }^{125}$ I to high specific activity. Biochim. Biophys. Acta. 251: 363-369.

18. David, G. S. 1972. Solid state lactoperoxidase: a highly stable enzyme for simple, gentle iodination of proteins. Biochem. Biophys. Res. Commun. 48: 464-471.

19. Curtis, C. G., K. L. Brown, R. B. Credo, R. A. Domanik, A. Gray, P. Stenberg, and L. Lorand. 1974. Calcium-dependent unmasking of active center cysteine during activation of fibrin stabilizing factor. Biochemistry. 13: 3774-3780.

20. Mosher, D. F. 1975. Cross-linking of cold-insoluble globulin by fibrin-stabilizing factor. J. Biol. Chem. 250: 66146621 .

21. Lorand, L., N. G. Rule, H. H. Ong, R. Furlanetto, A. Jacobsen, J. Downey, N. Oner, and J. Brunner-Lorand. 1968. Amine specificity in transpeptidation: Inhibition of fibrin cross-linking. Biochemistry. 7: 1214-1223. 
22. Mosher, D. F. 1976. Action of fibrin-stabilizing factor on cold-insoluble globulin and $\alpha_{2}$-macroglobulin in clotting plasma. J. Biol. Chem. 251: 1639-1645.

23. Gaffney, P. J., and A. N. Whitaker. 1979. Fibrin crosslinks and lysis rates. Thromb. Res. 14: 85-94.

24. Lorand, L., and A. Jacobsen. 1962. Accelerated lysis of blood clots. Nature (Lond.). 195: 911-912.

25. Gormsen, J., A. P. Fletcher, N. Alkjaersig, and S. Sherry. 1967. Enzymic lysis of plasma clots. The influence of fibrin stabilization on lysis rates. Arch. Biochem. Biophys. 120: 654-665.

26. McDonagh, R. P., J. McDonagh, and T. F. Ducker. 1971.
The influence of fibrin crosslinking on the kinetics of urokinase induced clot lysis. Br. J. Haemat. 21: 323-332.

27. Henderson, K. W., and M. Nussbaum. 1969. The mechanism of enhanced streptokinase-induced clot lysis following in vitro Factor XIII inactivation. Br. J. Haematol. 17: 445-453.

28. Haverkate, F. 1975. Lysis of cross-linked and non-crosslinked purified fibrin. Thromb. Diath. Haemorrh. 34: 584. (Abstr.)

29. Rampling, M. W. 1978. Factor XIII cross-linking and the rate of fibrinolysis induced by streptokinase and urokinase. Thromb. Res. 12: 287-295. 